\title{
Is endoscopic submucosal dissection really contraindicated for a large submucosal lipoma of the colon?
}

Endoscopic submucosal dissection (ESD) has recently been developed for endoscopic treatment of gastrointestinal tumors, enabling en bloc resection of even large tumors $[1,2]$. Although many endoscopists now perform ESD for earlystage gastric cancer, ESD has yet to be established as a safe therapy for colonic diseases, even in Japan. It is still unclear whether ESD is indicated for submucosal tumors (SMTs), and ESD for colonic diseases is still a controversial issue due to the considerable risk of perforation. In the pre-ESD era, SMTs required surgical treatment. Here we describe a unique case of a large submucosal lipoma of the colon which was successfully resected en bloc by ESD.

The patient was a 62-year-old woman with a giant SMT in the descending colon. Colonoscopic examination revealed a yellowish protruding submucosal tumor approximately $5 \mathrm{~cm}$ in diameter, suggesting that it might be totally resectable by ESD (๑ Figures $1 \mathbf{a}, \mathbf{b}$ ).

The technical aspects of our ESD procedure for this SMT are as follows. The first step was to create a sufficient submucosal fluid cushion to lift the tumor from the muscle layer. The submucosal injection solution was a mixture of $1 \% 1900-\mathrm{kDa}$ hyaluronic acid and $10 \%$ glycerin with $5 \%$ fructose plus $0.9 \%$ saline solution, with a small amount of indigo carmine and epinephrine [3]. The next step was to precut the surrounding mucosa and dissect the connective submucosal tissue under the SMT from the anal side while observing the lower surface of the tumor [4] (- Figures $\mathbf{1} \mathbf{b}, \mathbf{c}$ ). It was possible to make the giant SMT hang from the colonic wall by controlling the body position of the patient, and this made it easy to preserve the muscular layer ( $\bullet$ Figure $1 \mathbf{d}$ ).

ESD may be sufficient for en bloc resection of submucosal tumors in selected cases.

Endoscopy_UCTN_Code_TTT_1AQ_2AD

\section{K. Okada ${ }^{1}$, T. Shatari ${ }^{1}$, K. Suzuki ${ }^{2}$, \\ T. Tamada ${ }^{1}$, T. Sasaki ${ }^{1}$, T. Suwa ${ }^{1}$, M. Hori' ${ }^{3}$, M. Sakuma ${ }^{1}$}

Department of Surgery, Mito Red Cross Hospital, Sannomaru, Mito, Ibaraki, Japan

Department of Medicine, Mito Red Cross Hospital, Sannomaru, Mito, Ibaraki, Japan

Department of Pathology, Mito Red Cross Hospital, Sannomaru, Mito, Ibaraki, Japan

\section{References}

1 Yamamoto $H$. Endoscopic submucosal dissection of early cancers and large flat adenomas. Clin Gastroenterol Hepatol 2005; 3: S74-S76

2 Yamamoto H, Kawata H, Sunada Ket al. Successful en-bloc resection of large superficial tumors in the stomach and colon using sodium hyaluronate and small-caliber-tip transparent hood. Endoscopy 2003; 35 690-694

3 Fujishiro M, Yahagi N, Nakamura $M$ et al. Successful outcomes of a novel endoscopic treatment for GI tumors: endoscopic submucosal dissection with a mixture of highmolecular-weight hyaluronic acid, glycerin, and sugar. Gastrointest Endosc 2006; 63: 243-249

4 Yamamoto H, Kawata H, Sunada Ket al. Success rate of curative endoscopic mucosal resection with circumferential mucosal incision assisted by submucosal injection of sodium hyaluronate. Gastrointest Endosc 2002; 56: 507-512

5 Yamamoto $H$, Yube T, Isoda $N$ et al. A novel method of endoscopic mucosal resection using sodium hyaluronate. Gastrointest Endosc 1999; 50: 251 - 256

Bibliography

DOI $10.1055 / \mathrm{s}-2007-966405$

Endoscopy 2007; 39: 227

(c) Georg Thieme Verlag KG Stuttgart · New York . ISSN 0013-726X

\section{Corresponding author}

\section{K. Okada, MD}

Department of Surgery

Mito Red Cross Hospital

Sannomaru

Mito

Ibaraki 310-0011

Japan

Fax: +81-29-2270819

okada@is.icc.u-tokai.ac.jp
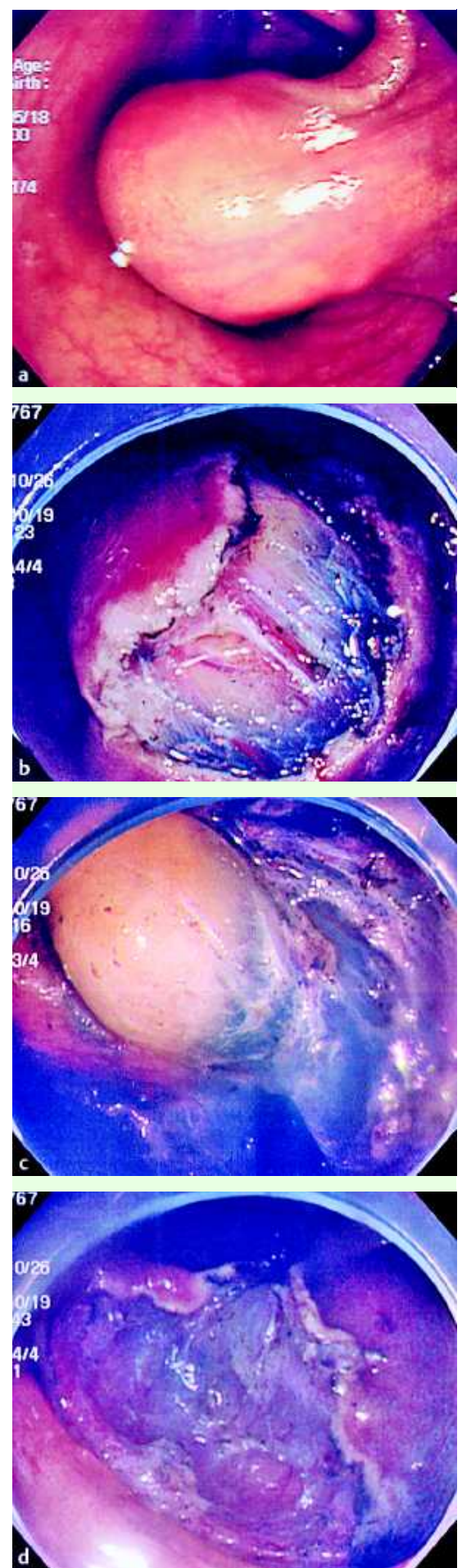

Figure 1 a Colonoscopic view of the large submucosal tumor. The tumor appears evaginated due to gravity, and hangs from the colon wall, suggesting that it would be resectable en bloc by ESD. $\mathbf{b}$ Marginal incision and submucosal dissection were performed using an electrocautery needle-knife in combination with a Hook knife (KD-620LR; Olympus, Tokyo, Japan). c After pre-cutting the surrounding mucosa from the anal side, the connective submucosal tissue under the SMT was dissected from the anal side while observing the tumor surface from beneath. $\mathbf{d}$ En bloc resection was achieved without complication. 